\title{
Analytical and Modelling Study on the Spatial Stress Distribution and Failure Process of Disc Specimen in the Brazilian Splitting Test
}

\author{
Wei Zhang, ${ }^{1,2}$ Wei-yao Guo $\mathbb{D}^{1,2}$ and Zhi-qi Wang ${ }^{2}$ \\ ${ }^{1}$ State Key Laboratory of Mining Disaster Prevention and Control Cofounded by Shandong Province and the Ministry of Science \\ and Technology, Shandong University of Science and Technology, Qingdao 266590, China \\ ${ }^{2}$ College of Mining and Safety Engineering, Shandong University of Science and Technology, Qingdao 266590, China
}

Correspondence should be addressed to Wei-yao Guo; 363216782@qq.com

Received 12 September 2021; Accepted 6 December 2021; Published 22 December 2021

Academic Editor: Yuanyuan Zha

Copyright (c) 2021 Wei Zhang et al. This is an open access article distributed under the Creative Commons Attribution License, which permits unrestricted use, distribution, and reproduction in any medium, provided the original work is properly cited.

To correctly obtain the spatial stress distribution and failure process of disc specimen in the Brazilian splitting test, an analytical solution of three-dimensional stress is deduced. Then, the effects of height-diameter ratio and clamp radian on the spatial stress distribution and failure process are analyzed and studied combined with numerical modelling. At last, the influence of spatial effect on the tensile strength of disc specimen is discussed. The results show that the cracks firstly generate at the two ends of the specimen in the axial direction and then extend due to the nonuniform distribution of tensile stress. The macrocracks coalescence does not mean the capacity loss of radial bearing. The maximum radial bearing capacity of the disc specimen decreases with the increase of height-diameter ratio due to the spatial effect. The tensile strength obtained by the twodimensional calculation formula is significantly smaller. Therefore, when the commonly-used height-diameter ratio of 0.5 is used in the Brazilian splitting test, a correction factor $k=1.15-1.25$ is suggested.

\section{Introduction}

The tensile strength of a rock is the ability of a rock specimen to resist damage under uniaxial tension, or ultimate strength, which is equal to the maximum tensile stress at failure in value. Tensile strength is an important mechanical property of rock, and it is also a control parameter for the safety and stability analysis of rock structure design, especially the surrounding rock mass in complex stress state in underground engineering construction. Due to the fixation difficulty and the end effect of specimen in the direct tensile test, the tensile strength of rock is generally determined by indirect methods, among which, Brazilian splitting test is commonly-employed and is recommended by ISRM [1-3]. In the Brazilian splitting test, the disc specimen experiences tensile failure because of the radial concentrating load, since the tensile strength of rock is much lower than that of the compressive strength. Besides, the tensile strength is calcu- lated by the analytical equation based on the maximum load [4]. In the test, the fact that disc specimen is subjected to radial load can be generally be simplified into plane issue, on which scholars have conducted lots of experimental and theoretical studies [5-8].

In the middle of the 20th century, researchers used Brazilian disc specimen to study the composite fracture problem of brittle materials. When studying the stress distribution on the disc surface, it is necessary to carry out power series expansion of the stress components. After some scholar's research, a five-item and approximation formula for $\sigma_{\theta}$ and $\tau_{r \theta}$ has been obtained, but the expansion form is so complex that the coefficient has no general solution, and the power series expansion of $\sigma_{r}$ is not obtained [9-11]. In order to comprehensively obtain the power series expansion of the Brazilian disc stress component and improve the calculation accuracy of the power-series solution, Dong et al. [12] put forward the power-series solution of the disc 
under concentrated load through mathematical analysis based on the analytical solution of the Brazilian disc stress component.

The main factors affecting Brazil's tensile strength formula are (1) the influence of stress space: Brazil's test is based on the analytical solution of plane elasticity stress, but in fact, it is in a three-dimensional stress state. The two can cause as much as the first principal stress. The error of about $10 \%$ is one of the main reasons for the difference between the Brazilian test and the uniaxial tensile strength of rock. (2) The traditional formula does not reflect the influence of material Poisson's ratio and sample heightdiameter ratio on the tensile strength. In fact, Poisson's ratio and sample height-diameter ratio have a certain influence on the stress distribution, which in turn affects the accuracy of the obtained strength. (3) Arc loading in contact with the rock will cause stress concentration in the loading area. Excessive stress concentration will cause local damage in the loading area, resulting in a big difference between the strength of the Brazilian disc and the actual value.

The rock specimen in the splitting test is actually a threedimensional force entity. Considering the difficulty of machining and the accuracy, the requirement of the heightto-diameter ratio of the disc specimen is $0.5-1.5$, which can hardly satisfy the assumption of the plane problem. Chau and Wei [13] conducted a theoretical study on the spatial stress distribution of the Brazilian splitting test earlier and derived the analytical solution of the spatial stress on the two sides of the cylindrical specimen. The results show that the maximum tensile stress at the two ends of the disc exceeds $10 \%$ of the center point when the height-diameter ratio is greater than 0.5 . The specific difference increases with the increase of the aspect ratio, and it is related to the material Poisson's ratio. Thuro et al. [14] conducted a Brazilian splitting test on different aspect ratios when studying the scale effect on rock strength characteristics, and the results reflected that the tensile strength of the specimen decreases with increasing aspect ratio.

The above theoretical analysis is just about stress state analysis based on elastic deformation without considering the plastic deformation before the rock failure and the entire failure process. In view of that, Yu [15] found out that the tensile stress on the end face is larger than that on the middle after the three-dimensional finite element calculation, and the maximum value is larger than the analytical value calculated by the two-dimensional disc. Therefore, it is considered that the true tensile strength of the three-dimensional disc specimen is greater than the two-dimensional analytical calculation value. Zhu and Tang [16] obtained a stress-load variation curve similar to the actual test through analyzing the failure process of a two-dimensional disc with RFPA. Meng et al. [17] have used PFC to simulate the Brazilian splitting test on the two-dimensional platform disc while the simulated damage and its shape distinct from the actual one. Nevertheless, Wang et al. [18] used the CDEM model to simulate Brazilian disc test on the two-dimensional platform. The test indicated that both the process of crack propagation and the relationship of deformation displacement are close to the actual test.
The problem with the Brazilian test method is that the formula for calculating the tensile strength comes from the elasticity analytical solution of the plane stress problem, while the force on the sample in the actual test is a threedimensional mechanical problem. Moreover, the commonly used sample height to diameter ratio is 0.5 to 1.0 , and it is even more difficult to ensure that the stress state of the sample can be simplified into a plane stress or plane strain problem. The stress of the sample under three-dimensional conditions is much more complicated than under twodimensional conditions. It can be inferred that the stress distribution on different cross-sections of the sample varies along the thickness direction. Therefore, it is untrue to calculate the tensile strength of rock-like materials with the formula of the plane condition, at least it is not accurate enough. In fact, it has been pointed out in the literature that the tensile strength of a material measured by the Brazilian test method is not equal to the tensile strength of the same material measured by the direct tensile method. However, due to various reasons, no one has developed a traditional tensile strength calculation formula. Therefore, it is very necessary to use the three-dimensional elastic theory to derive the three-dimensional stress distribution law of the Brazilian test, but only a small number of scholars are conducting exploratory research in this area. Fortunately, this fundamental subject can be studied with the aid of modern threedimensional finite element mechanical analysis.

In this paper, an analytical solution of three-dimensional stress of the disc specimen is deduced. Then, the effects of height-diameter ratio and clamp radian on the spatial stress distribution and failure process are analyzed and studied combined with numerical modelling. At last, the influence of spatial effect on the tensile strength of disc specimen is discussed, and a correction factor $k$ in the Brazilian splitting test is given.

\section{Spatial Stress Distribution of Brazilian Disc}

2.1. Numerical Simulation Results. The geometric model and loading condition of the three-dimensional Brazilian disc are shown in Figure 1. The three-dimensional stress distribution of typical Brazilian disc is firstly simulated. The diameter and thickness of the disc are $50 \mathrm{~mm}$ and $25 \mathrm{~mm}$, respectively, i.e., the height-diameter ratio is 0.5 . The elastic modulus is $4.5 \mathrm{GPa}$, the cohesion is $4.5 \mathrm{MPa}$, the tensile strength is $10.5 \mathrm{MPa}$, the position ratio is 0.25 , and the density is $2250 \mathrm{~kg} / \mathrm{m}^{3}$.

The stress distribution of the Brazilian disc in the three directions is illustrated in Figure 2. As shown in Figure 2(a), the stress becomes the largest in the center of the disc in the horizontal direction where $\sigma_{y}$ is three times of $\sigma_{x}$. As $x$ increases, the absolute values of $\sigma_{x}$ and $\sigma_{y}$ decrease until to zero in the disc boundary. As shown in Figure 2(b), $\sigma_{x}$ is almost a constant while $\sigma_{y}$ is a parabola in the vertical direction except the stress concentration at the disc boundary. The results are similar to the theoretical analysis [19].

As shown in Figure 2(c), the tensile stress and compressive stress are not constant at the central $z$-axis. The two 


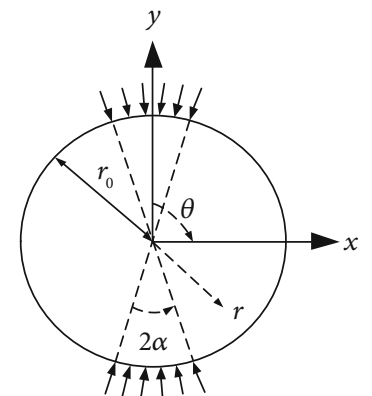

(a) Stress distribution of the surface

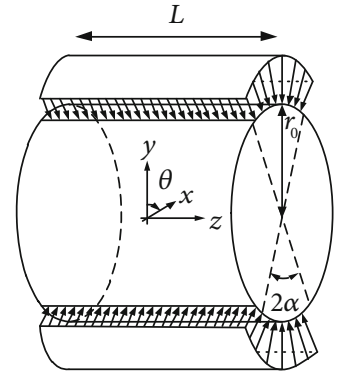

(b) Three-dimensional stress distribution

Figure 1: Three-dimensional mechanical model of Brazilian disc.

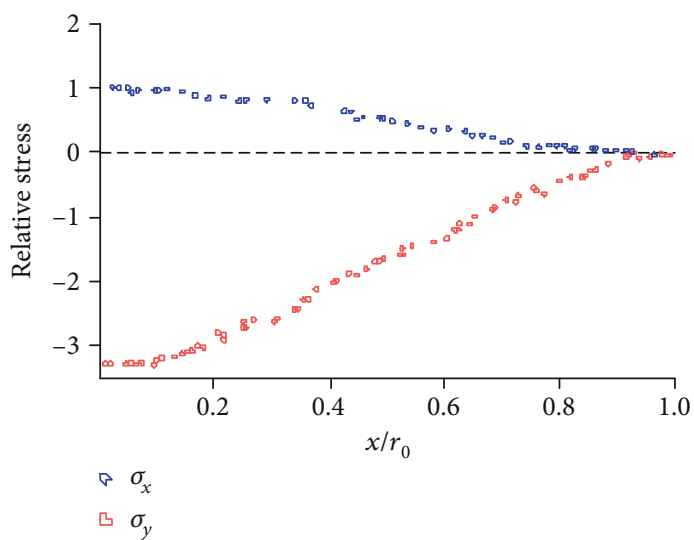

(a) $x$-axis

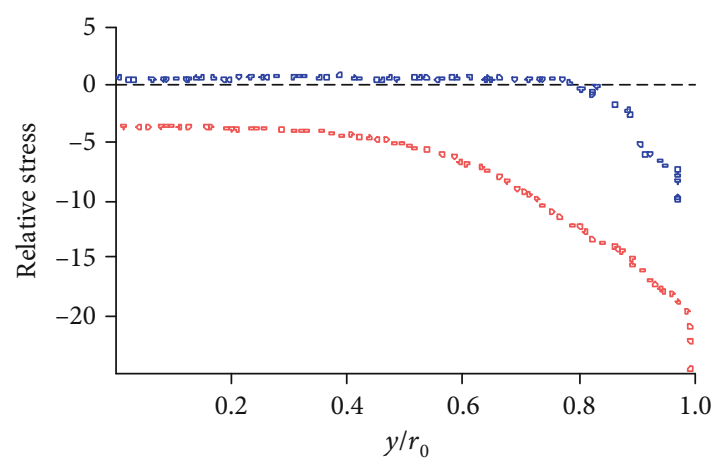

ค $\sigma_{x}$

凸 $\sigma_{y}$

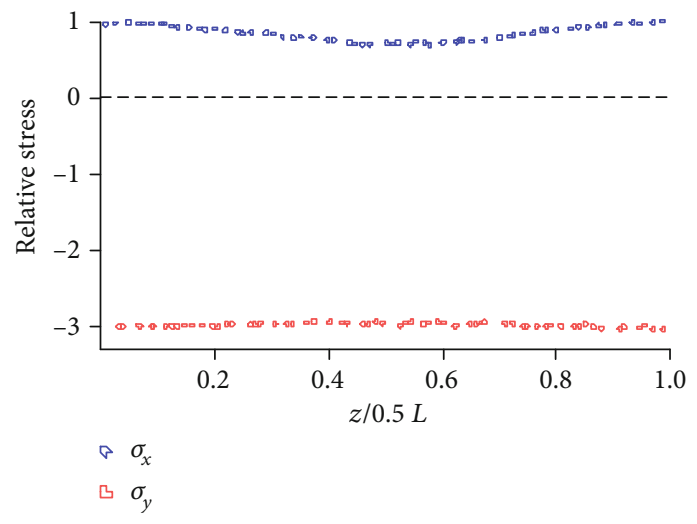

(c) $z$-axis

Figure 2: Stress distribution of the Brazilian disc in the three directions.

stresses are low in the middle while high at both ends, which are symmetrically distributed. The tensile and compressive stresses are the minimum at $z=0.5 \mathrm{~L}$, while the maximum at both ends, which means that the stress distribution of the disc specimen has spatial effect. The results are the same as those of analytical calculation and finite element modelling [20-22].

2.2. Calculation Verification of Analytical Solution. According to the three-dimensional liner elastic hypothesis of rock mechanics, the spatial stress state of the Brazilian disc must meet 21 basic control equations with equilibrium, deforma- tion, coordination, and material constitution. The unknown elastic field variables include 6 strain-displacement relationships (Eq. (1)), 3 equilibrium equations (Eq. (2)), 6 compatibility equations (Eq. (3)), and 6 material constitutive equations (Eq. (4)) [23]. In this paper, when the above equations satisfy the small deformation, then

$$
\begin{aligned}
\varepsilon_{i j} & =\frac{1}{2}\left(u_{i, j}+u_{j, i}\right), \\
\sigma_{i j, j}+F_{i} & =0,
\end{aligned}
$$




$$
\begin{gathered}
e_{i j k} e_{p q r} \frac{\partial^{2} \varepsilon_{j q}}{\partial x_{k} \partial x_{r}}=0, \\
\sigma_{i j}=\lambda \delta_{i j} \varepsilon_{k k}+2 \mu \varepsilon_{i j},
\end{gathered}
$$

where $\varepsilon$ is the strain; $u$ is the displacement; $u_{i, j}$ is the derivative of $i$ with respect to $j ; \sigma$ is the stress; $F_{i}$ is the physical component along $i$-axis; $e_{i j, k}$ is the permutation symbol; $\delta_{i j}$ is the Kronecker function; $\mu$ and $\lambda$ are Ramon constants.

To simplify the above equations and obtain the exact solution of the basic elastic equation, the stress and stress variables in the system are eliminated [24]. Homogeneous isotropic elastic equation is reformed based on the displacement component, which can be expressed as follows:

$$
(\lambda+\mu) \nabla(\nabla \cdot \mu)+\mu \nabla^{2} \mu+F=0 .
$$

According to the spatial stress theory [25], Eq. (5) can be modified as follows:

$$
\begin{aligned}
\sigma_{r r}= & -\frac{2 p}{\pi}\left\{\alpha+\sum_{n=1}^{\infty}\left[1-\left(1-\frac{1}{n}\right) \frac{r^{2}}{r_{0}^{2}}\right]\left(\frac{r}{r_{0}}\right)^{2 n-2}\right. \\
& \times \sin (2 n \alpha) \cos (2 n \theta)\}, \\
\sigma_{\theta \theta}= & -\frac{2 p}{\pi}\left\{\alpha-\sum_{n=1}^{\infty}\left[1-\left(1+\frac{1}{n}\right) \frac{r^{2}}{r_{0}^{2}}\right]\left(\frac{r}{r_{0}}\right)^{2 n-2}\right. \\
& \times \sin (2 n \alpha) \cos (2 n \theta)\},
\end{aligned}
$$

where $r$ and $\theta$ are the coordinates of the disc surface; $r_{0}$ is the radius of the disc; $P$ is the vertical loading force; $L$ is the thickness of the disc; $\alpha$ is the loading radian.

The above equations are the two-dimensional stress state of the disc surface. To obtain the spatial stress distribution, the series expansion and numerical integration of $z$-axis stress are employed to get the following equations:

$$
\begin{aligned}
\sigma_{r r(r, \theta, z)}= & -\frac{4 p}{\pi \alpha L} \sum_{n=1}^{\infty}\left(\frac{r}{r 0}\right)^{2 n-2} \\
& \cdot\left(\frac{\alpha}{2}+\sum_{m=2,4,6}^{\infty} \frac{3 \sin (m \alpha)-3 m \alpha \cos (m \alpha)}{m^{3} \alpha^{2}} \frac{r^{2}}{r_{0}^{2}} \cos (m \theta)\right) \\
& \times \frac{(1-\cos (n \pi)) \sin (n \pi / 2)}{n \pi} \cos \left(\beta_{n} z\right),
\end{aligned}
$$

$$
\begin{aligned}
\sigma_{r r(r, \theta, z)}= & -\frac{4 p}{\pi \alpha L} \sum_{n=1}^{\infty}\left(\frac{r}{r 0}\right)^{2 n-2} \\
& \cdot\left(\frac{\alpha}{2}-\sum_{m=2,4,6}^{\infty} \frac{3 \sin (m \alpha)+3 m \alpha \cos (m \alpha)}{m^{3} \alpha^{2}} \frac{r^{2}}{r_{0}^{2}} \cos (m \theta)\right) \\
& \times \frac{(1-\cos (n \pi)) \sin (n \pi / 2)}{n \pi} \cos \left(\beta_{n} z\right),
\end{aligned}
$$

where $z$ is the coordinate of the spatial position; $\beta_{n}=n$ $\pi / 4 \mathrm{~L}$.

The spatial stress distribution of the Brazilian disc $(L / D=0.5$ and $\mu=0.25)$ calculated by the above equations is illustrated in Figure 3, which reveals that evolution law of spatial stress distribution is similar to that of numerical simulation. Thus, it can be concluded that the stress distribution has spatial effect, and that it is also influenced by the loading radian.

\section{Effect of Height-Diameter Ratio on the Spatial Stress Distribution}

Due to the spatial effect of tensile stress in the Brazilian splitting test, the effect of height-diameter ratio cannot be ignored. In this section, ANSYS is firstly adopted to establish the three-dimensional Brazilian disc model with the loading radian of $20^{\circ}$, and then it is imported into FALC3D for numerical simulation analysis. The height-diameter ratios are set as $0.25,0.5,0.75,1.0,1.25,1.5,1.75,2.0$, and 2.25, respectively. The origin of the coordinate is located at the center of the disc.

Figure 4 illustrates the tensile stress distribution on the central axis of the disc specimen through numerical simulation, while Figure 5 shows the evolution law of the maximum and the minimum tensile stresses on the central axis of the specimen with different height-diameter ratios by theoretical calculation.

As shown in Figure 4, the tensile stress distribution on the central axis is closely related to the height-diameter ratio. When the height-diameter ratio is less than 1.0, the tensile stress on the specimen end increases with the increase of height-diameter ratio, while the tensile stress at the center shows an opposite trend. When the height-diameter ratio exceeds 1.0, the increasing trend of tensile stress on the end face and middle section slows down, and the position of minimum tensile stress on the central axis experiences offset to the end face. The effect of height-diameter ratio on the tensile stress distribution on the central axis can be summarized as follows. When the height-diameter ratio increases from 0 , the tensile stress of central axis is a curve with low midpoint and high ends, where the maximum stress increases while the minimum decreases. However, when the height-diameter ratio increases to 1.0, the variation rate of spatial effect reaches the maximum. As the heightdiameter ratio continues increasing, the varied range of the maximum and the minimum tensile stresses decreases, at which time the position of the minimum value changes and approaches to the end face while the stress near the midpoint experiences an increasing tendency.

When the height-diameter ratio is small, the Brazilian disc approximates the plane stress state in two-dimensional analytical calculation. On the contrary, when the heightdiameter is large, the midsection of the specimen is close to the plane strain state. However, when approaching to the two end faces, it is a curve, as shown in Figure 5. Besides, the maximum and minimum tensile stresses on the central axis are also related to Poisson ratio $[26,27]$. The influence 


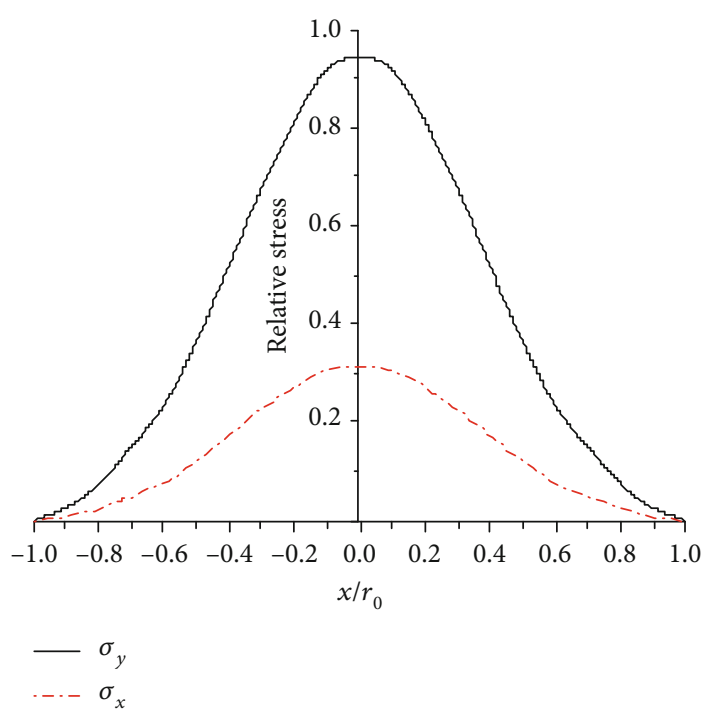

(a) $x$-axis stress distribution

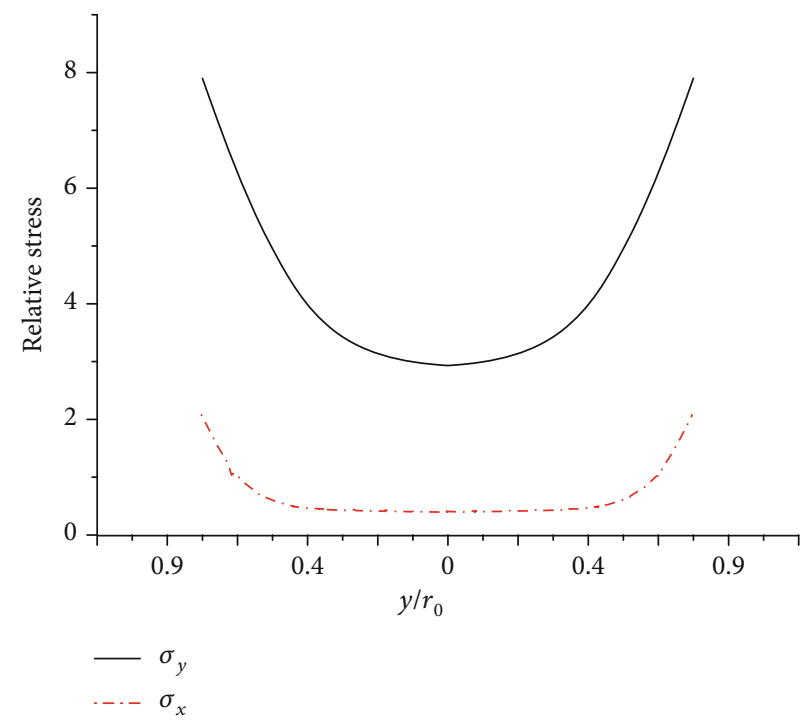

(b) $y$-axis stress distribution

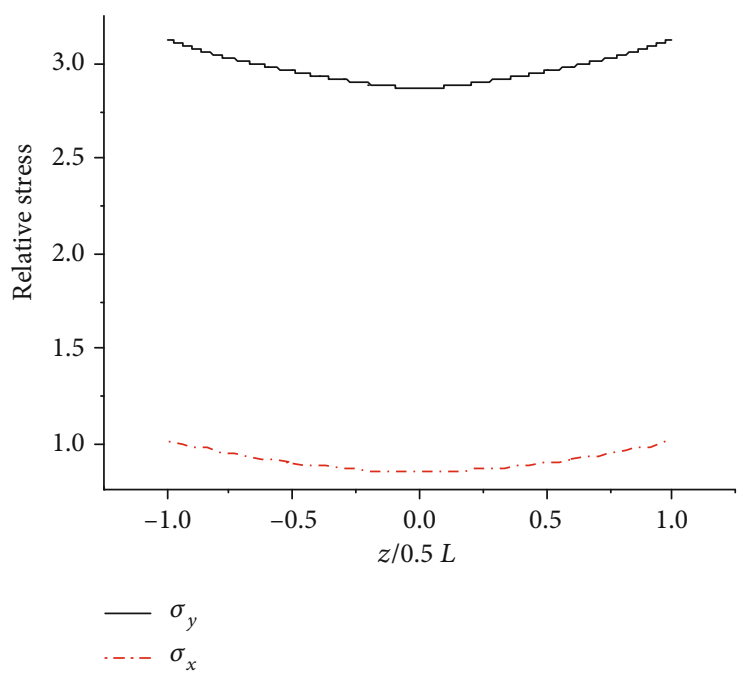

(c) $z$-axis stress distribution

Figure 3: Numerical simulation of three-direction stress distribution of Brazilian disc specimen.

of Poisson ratio on the spatial effect of tensile stress is not so significant as that of height-diameter ratio since the Poisson ratio of most rocks is $0.15-0.35$ and floats around 0.25 . Therefore, the influence of Poisson can be ignored in most cases.

\section{Effect of Clamp Radian on the Spatial Stress Distribution}

To ensure the crack initiation at the center of the disc, loading radian needs to satisfy $\alpha \geq 10^{\circ}$. However, when the loading radian is too large, the stress at the center not only depends on the resultant force at the loading end. The failure mode of the disc transforms from simple splitting to complex fracture way. Thus, the selection of loading radian is also the research priority [28-31]. The recommended values in current studies are $10-30^{\circ}$ despite the material properties and boundary conditions are slightly different. In this sec- tion, the three-dimensional Brazilian disc model is established with the loading radians of $10^{\circ}, 14^{\circ}, 18^{\circ}, 22^{\circ}, 26^{\circ}$, and $30^{\circ}$, respectively, by ANSYS, which is then imported into FALC3D for numerical simulation analysis. The height and diameter are set to be $50 \mathrm{~mm}$ and $20 \mathrm{~mm}$, respectively.

The stress distribution is very complex for the threedimensional models. To clearly show the stress variation, the central circular section $(z=0)$ and the specimen surface $(z= \pm 12.5 \mathrm{~mm})$ are selected for analysis. First, the disc specimens with loading radians of $10^{\circ}, 14^{\circ}$, and $18^{\circ}$ are analyzed. For the central circular section $(z=0)$, the equivalent stresses on the compression plane $(x=0 \mathrm{~mm})$ and vertical plane $(x= \pm 5 \mathrm{~mm})$ are compared, as shown in Figure 6 . The equivalent stress on the compression plane gently varies in the middle part, but the trend of the stress variation changes at the position $3 \mathrm{~mm}$ away from the platform with the small variation amplitude and the low equivalent stress. The maximum value exists in the central position. On the 


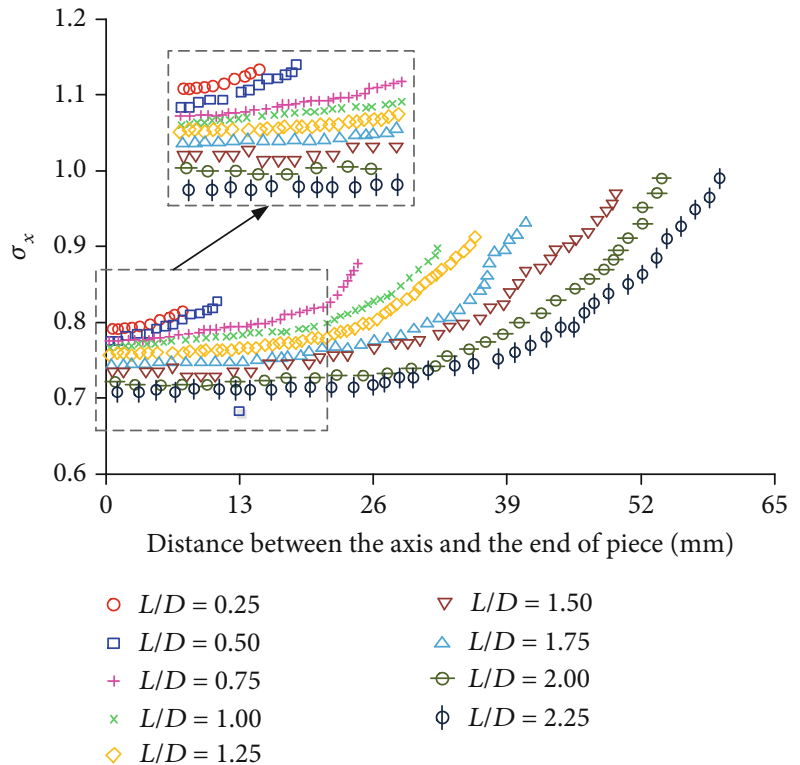

FIgURE 4: Tensile stress distribution on the central axis of different height to diameter ratio samples.

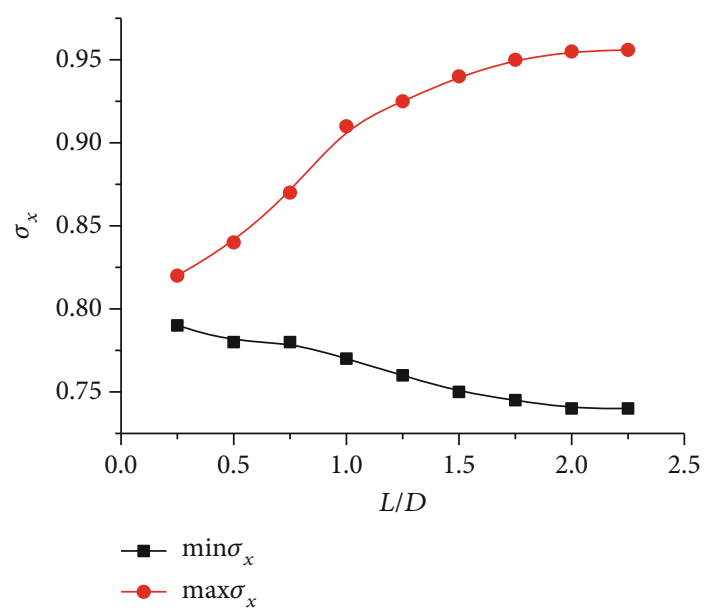

Figure 5: Effect of height-diameter ratio on maximum and minimum tensile stress of axial center of specimen.

other hand, the equivalent stress on the vertical plane also varies slightly in the middle region although the stress level is smaller than that of the compression plane. The stress curve mutates at the position $5 \mathrm{~mm}$ away from the specimen edge, where the equivalent stress sharply increases, and the maximum equivalent stress appears at the specimen edge. The results above reveal the fact that the most likely crack initiation point is the specimen edge, and the second possible position is the center of the compression plane.

For the specimen surface $(z= \pm 12.5 \mathrm{~mm})$, the equivalent stresses on the compression plane $(x=0 \mathrm{~mm})$ and on the vertical plane $(x= \pm 5 \mathrm{~mm})$ are compared, as shown in Figure 7. The stress distribution shows M-shape on the compression plane with the maximum equivalent stress located

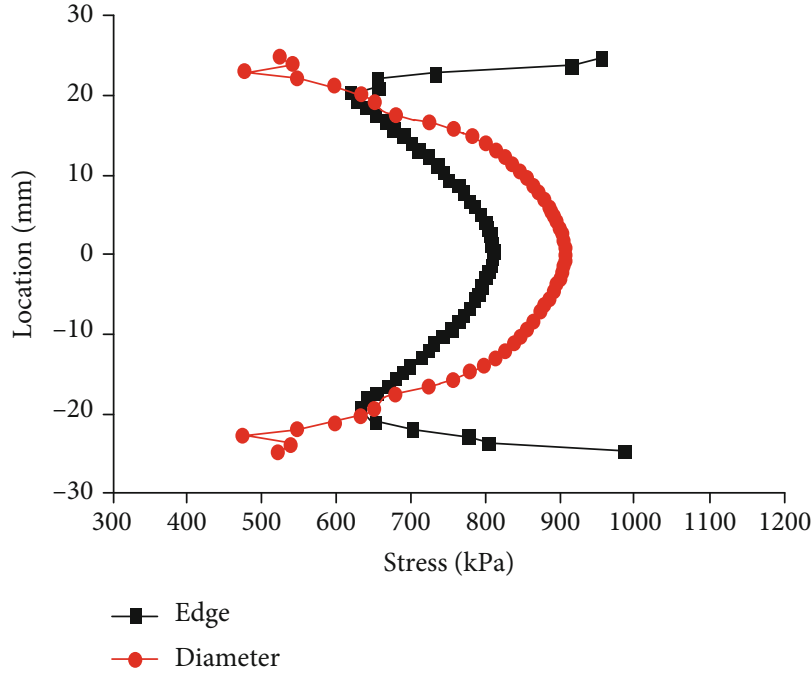

FIgURE 6: Central circular section equivalent stress distribution $\left(10^{\circ}, 14^{\circ}\right.$, and $\left.18^{\circ}\right)$.

about $10 \mathrm{~mm}$ near the edge. In contrast, the equivalent stress on the vertical plane in the middle part distributes uniformly and the stress level is low. As near the specimen edge, the stress sharply increases and induces a high stress concentration area, higher than that of other positions. The equivalent stress here is the maximum in the disc. Additionally, the equivalent stress on the specimen surface is larger than that on the corresponding position of the central circular section.

Similarly, for the disc specimens with the loading radians of $22^{\circ}, 26^{\circ}$, and $30^{\circ}$, the equivalent stresses on the compression plane $(x=0 \mathrm{~mm})$ are shown in Figure 8 . The equivalent stress is the largest at the central position and uniformly decreases from the central to the edge. At the position $9 \mathrm{~mm}$ away from the edge, the variation rate experiences great change indicating that the direction of the main stress may vary. On the vertical plane $(x= \pm 6.47 \mathrm{~mm})$, the equivalent stress in the middle region decreases from midpoint to the two sides, and the value is less than that of the corresponding position on the compression plane. The stress cure mutates $13 \mathrm{~mm}$ away from the platform, which is followed by a rapid increase. The maximum equivalent stress appears on the disc edge. Although the maximum equivalent stress is located in the specimen center, the equivalent stress on the edge is almost equal to it, which means the disc edge is also likely to crack.

For the specimen surface $(z= \pm 12.5 \mathrm{~mm})$, the equivalent stress distributions are illustrated in Figure 9. Different from the cases where the loading radians are $10^{\circ}, 14^{\circ}$, or $18^{\circ}$, the stress distribution on the compression plane is not M-shape, but convex-shape. The equivalent stress decreases gradually from the center to the two sides. Its value is larger than that of the corresponding position in the central circular section. On the vertical plane $(x= \pm 6.47 \mathrm{~mm})$, the equivalent stress is not high in the middle, but increases sharply near the specimen edge. Thus, high-stress concentration area forms. Such a phenomenon reveals that the crack may also start from the disc edge. 


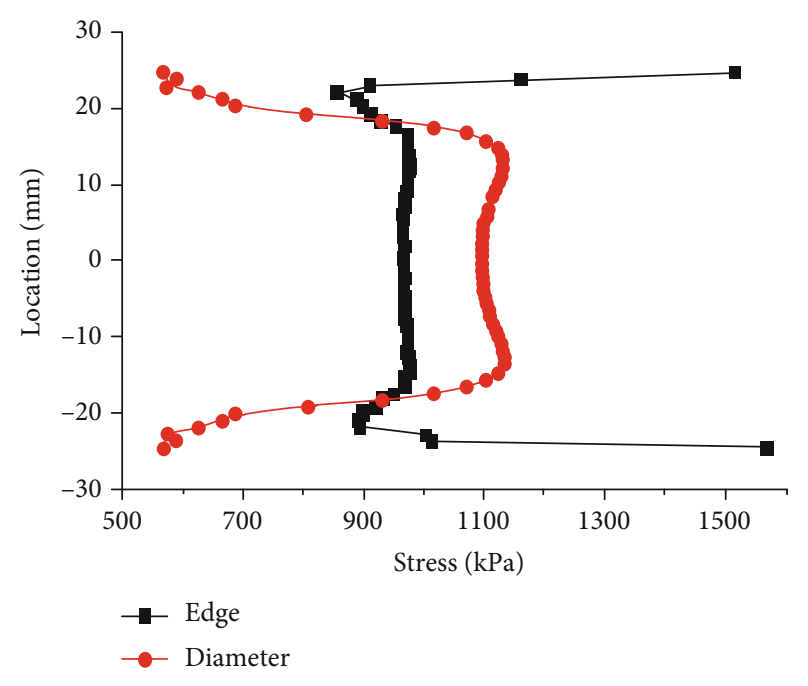

FIGURE 7: Equivalent stress distribution on the specimen surface $\left(10^{\circ}, 14^{\circ}\right.$, and $\left.18^{\circ}\right)$.

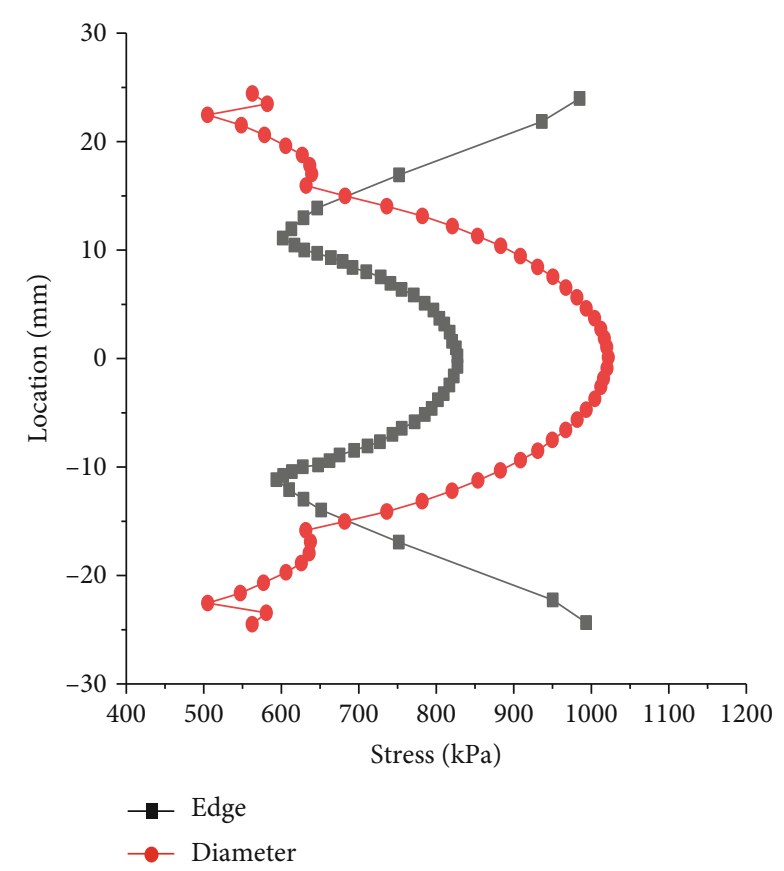

Figure 8: Central circular section equivalent stress distribution $\left(22^{\circ}, 26^{\circ}\right.$, and $\left.30^{\circ}\right)$.

\section{Influence of Spatial Stress Effect on the Disc Failure}

Since the ratio of compressive strength to tensile strength of rock material is much larger than 3 , it is considered that the failure of the disc specimen is caused by the tensile stress in the specimen center. The tensile strength can be calculated as follows:

$$
\sigma_{t}^{\prime}=k \frac{2 P}{\pi D H}=0.637 \frac{P}{D H},
$$

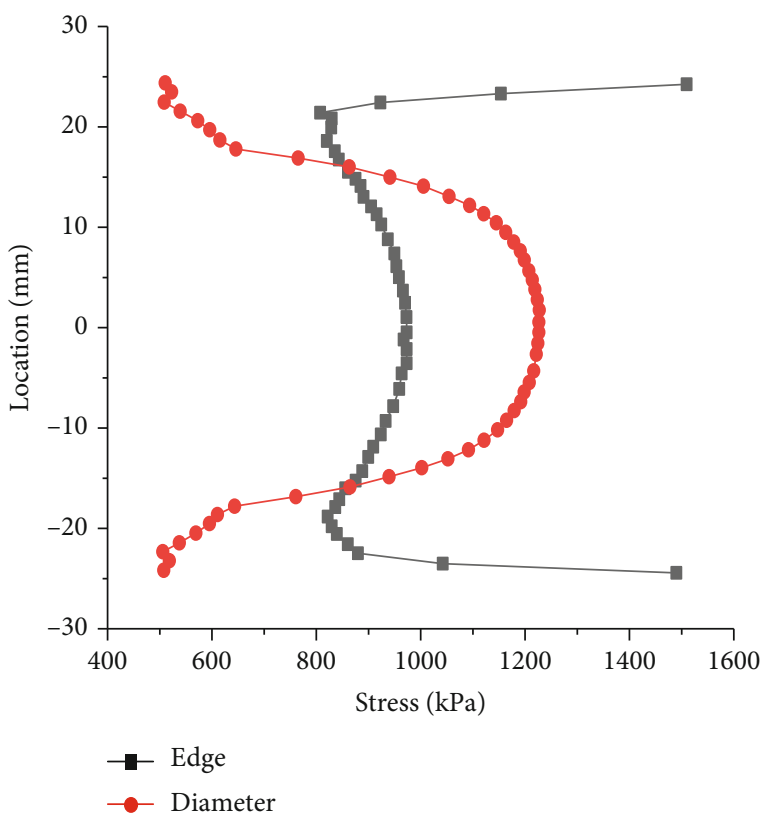

FIgURE 9: Equivalent stress distribution on the specimen surface $\left(22^{\circ}, 26^{\circ}\right.$, and $\left.30^{\circ}\right)$.

According to the spatial stress analysis, it is concluded that the distribution of tensile stress on the central axis is closely related to the height-diameter ratio. When the height-diameter ratio is less than 1.0, the tensile stress on the disc edge increases with the increase of heightdiameter ratio. The maximum value exceeds 1.25 times of that calculated by Eq. (10). On contrast, the tensile stress on the specimen center decreases as increasing the heightdiameter ratio. When the height-diameter ratio is 1.0 , the tensile stress is only 0.9 times of the calculated value. When the height-diameter ratio exceeds 1.0, the tensile stress on the edge no longer increases but remains at about 1.2 times. However, the tensile stress on the center shows a rising trend with the minimum tensile stress on the central axis offset to the end face. The minimum tensile stress is still about 0.9 times.

When the height-diameter ratio is small, the Brazilian disc approximates the plane stress state indicating that the tensile stress on the central axis is close to the calculation results of Eq. (10). When the height-diameter ratio is relatively large, the tensile stress on the middle section of the specimen is also close to that of the plane, which is basically consistent with the calculation results. However, the stress is a curve near the two face ends, as shown in Figure 10. The above spatial stress analysis reveals that when the height-diameter ratio is $0.5-1.0$, the maximum error is over $20 \%$ compared with the two-dimensional analytical value. In other words, the calculated strength obtained by Eq. (10) is small, and minimum is only 0.8 times of the actual strength.

Therefore, the spatial effect of three-dimensional disc specimens cannot be ignored. As a comparison, Figure 11 illustrates the curves of central point stress $\sigma_{x}$ and loading point stress $\sigma_{y}$ of the two-dimensional Brazilian disc 


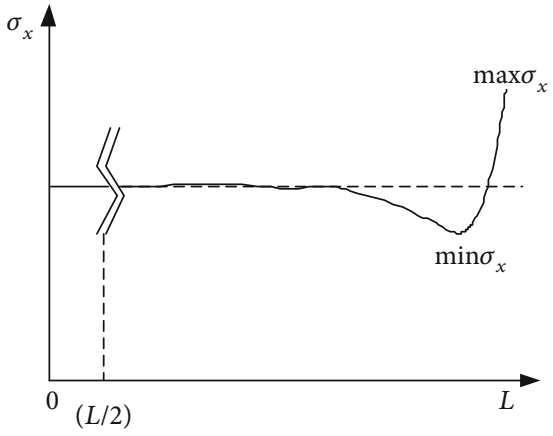

Figure 10: The distribution of the tensile stress on the central axis when the height-diameter ratio $L / D$ is large enough.

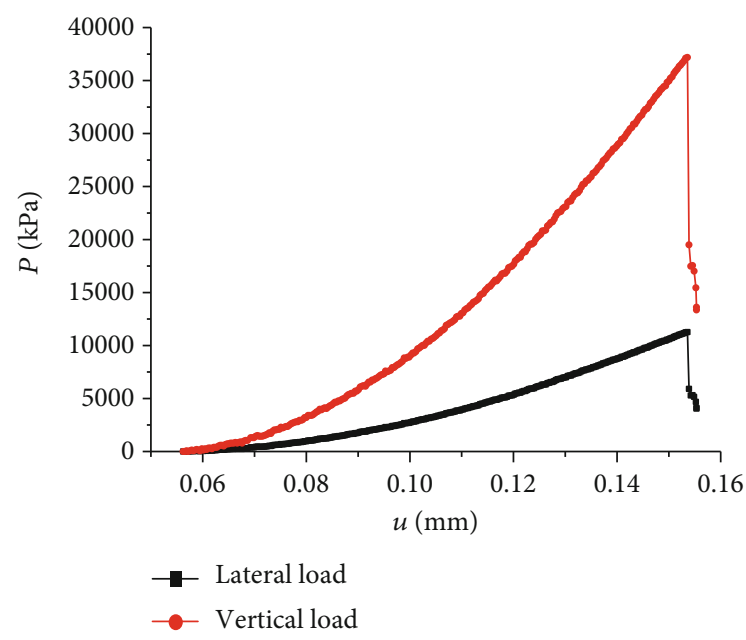

FIGURE 11: Displacement-center point tension stress and load point vertical stress.

specimens. In the two-dimensional state, the maximum loading stress is obviously larger than that under threedimensional condition. Another interesting phenomenon is that the maximum tensile stress and the compressive stress nearly simultaneously appear on the two-dimensional disc, that is, the generation and propagation of macroscopic cracks instantly complete. Besides, the macroscopic failure of the three-dimensional specimen is progressive. The spatial distribution of the tensile stress further extends the crack propagation process, leading to the lag of the peak compressive stress. Consequently, the tensile strength calculated with the maximum load is larger than that of the actual splitting state of the Brazilian specimen.

Although the tensile strength is overestimated due to the lag of the peak compressive stress, the maximum loading stress of the three-dimensional disc is still smaller than that of the two-dimensional disc, as shown in Figure 12. When the height-diameter ratio is larger than 0.5 , the maximum vertical stress remains steady. For the commonly used height-diameter ratio of 0.5-1.0, the tensile strength of the three-dimensional disc calculated with the maximum loading is 0.82 times of the value calculated by Eq. (10).

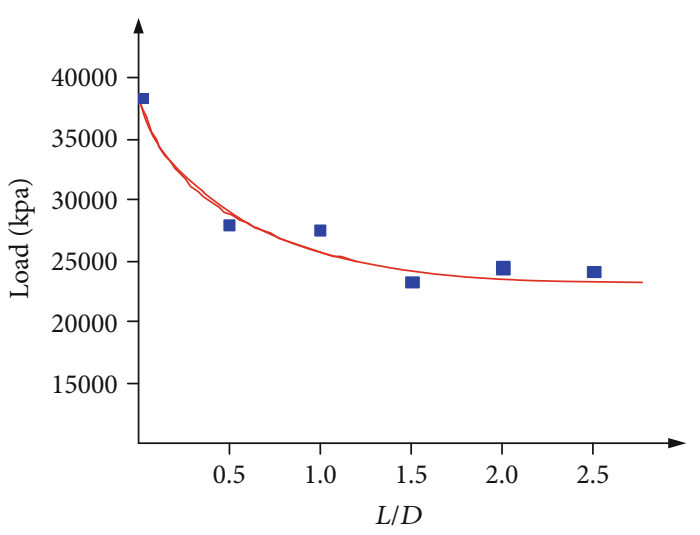

FIgURE 12: Influence of different height-diameter ratios on the maximum loading stress

\section{Discussions}

The Brazilian disc is in a three-dimensional state in the actual test. There is no pure tensile stress when subjected to radial loading because of the complicated stress distribution. The elements in the middle of the specimen are under the three-dimensional stress state, but those near the two ends are under the two-dimensional stress state. Thus, stress concentration inevitably appears near the ends under elastic equilibrium condition. Fortunately, the concentration only reaches a certain degree, which means that the spatial effect has the upper limit.

The commonly used height-diameter ratio is 0.5. The $\sigma_{t}{ }_{t}$ indicates the modified Brazilian disc tensile strength. The variation of Poisson ratio is small. Thus, a correction factor $k$ considering the spatial effect can be introduced to modify the test results. According to the above analysis, $k$ can be taken within the range of 1.15-1.25 (Note: when the Poisson ratio is small, the small value is chosen; when the Poisson ratio is large, the large value is chosen.). Equation (10) can be rewritten as follows:

$$
\sigma_{t}^{\prime}=k \frac{2 P}{\pi D H}
$$

As an indirect method to measure the tensile strength, the accuracy of Brazilian splitting test is also affected by other factors. From the point of stress state analysis, the existence of compressive stress leads to easier tensile failure. The Brazilian splitting strength is lower than the uniaxial tensile strength. From the point of heterogeneity, the failure always occurs in the desired location and not necessarily in the weakest part. This phenomenon will cause a large test result.

Additionally, different loading methods also lead to different load distributions, which means the loading mode is another essential factor on the results of Brazilian splitting test. Plate loading belongs to linear load. This loading method can easily induce stress concentration of the loading end. The disc specimen ends will first fail due to compression. This result violates the basic hypothesis of twodimensional elastic mechanics theory. The specimen failure 
is not caused by the tensile stress in the disc center. There are some differences between the test value and real value. The tensile strength obtained by the arc indenter loading is larger than or equal to the direct tensile strength [32], while the tensile strength measured by the rigid plate loading is less than the direct tensile strength [33].

Arc indenter loading is widely used. Such a loading method can improve the stress concentration of the loading end, avoiding the compression failure of the specimen end. The effectiveness of the Brazilian splitting test is therefore guaranteed. Although the tension-compression ratio measured by the plate loading is in the reasonable range. The specimen failure due to end pressure always appear [34]. Therefore, the uniform loading can be ensured using arch indenter loading, improving the stress concentration.

\section{Conclusions}

This paper first gives an analytical solution of the threedimensional stress of disc specimen, and then the effects of height-diameter ratio and clamp radian on the spatial stress distribution and failure process are analyzed and studied combined with numerical modelling. The main conclusions are as follows:

(1) The stress distribution law on the cross-section perpendicular to the central axis is similar to the results of the two-dimensional analytical method. However, the tensile stress on the central axis is not constant and an obvious spatial effect exists, that is, the tensile stress is high in the ends but low in the middle

(2) When the height-diameter ratio is less than 1.0, the maximum tensile stress on the two ends of the disc specimen increases with increasing the heightdiameter ratio, while decreases in the middle part. When the height-diameter ratio is larger than 1.0, the maximum and minimum tensile stresses keep steady, indicating that the influence of spatial effect reaches the upper limit. The maximum increasing range is nearly $20 \%$. Thus, when the commonlyused height-diameter ratio of 0.5 is used in the Brazilian splitting test, a correction factor $k=1.15-$ 1.25 is suggested

(3) The increase of arc loading angle can significantly improve the stress concentration of the loading point and reduce the possibility of compression failure. However, the tensile stress and the tensile zone will gradually decrease, which is unfavorably guaranteed for the crack initiation in the center of the Brazilian disc. The optimal arc loading angle is $20-30^{\circ}$

\section{Data Availability}

All data included in this study are available upon request by contact with the corresponding author.

\section{Conflicts of Interest}

The authors declare that they do not have any commercial or associative interest that represents a conflict of interest in connection with the work submitted.

\section{Acknowledgments}

The research described in this paper was financially supported by Major Scientific and Technological Innovation Project of Shandong Provincial Key Research Development Program (no. 2019SDZY02), National Natural Science Foundation of China (no. 51904165), and Shandong Provincial Natural Science Foundation (no. ZR2019QEE026).

\section{References}

[1] S. F. Wang, Y. Tang, X. B. Li, and K. Du, "Analyses and predictions of rock cuttabilities under different confining stresses and rock properties based on rock indentation tests by conical pick," Transactions of Nonferrous Metals Society of China, vol. 31, no. 6, pp. 1766-1783, 2021.

[2] Q. Z. Wang, W. Li, and H. P. Xie, "Dynamic split tensile test of flattened Brazilian disc of rock with SHPB setup," Mechanics of Materials, vol. 41, no. 3, pp. 252-260, 2009.

[3] C. F. Markides and S. K. Kourkoulis, "The stress field in a standardized Brazilian disc: the influence of the loading type acting on the actual contact length," Rock Mechanics and Rock Engineering, vol. 45, no. 2, pp. 145-158, 2012.

[4] C. F. Markides, D. N. Pazis, and S. K. Kourkoulis, "The centrally cracked Brazilian disc: closed solutions for stresses and displacements for cracks under opening mode," Journal of Engineering Mathematics, vol. 83, no. 1, pp. 143-168, 2013.

[5] Y. U. Yong and P. Chen, "Spatial distribution of tensile stress in Brazilian disc test of rock," Rock and Soil Mechanics, vol. 26, no. 12, pp. 1913-1916, 2005.

[6] M. Zakeri, M. R. Ayatollahi, and M. Guagliano, "A photoelastic study of T-stress in centrally cracked Brazilian disc specimen under mode II loading," Strain, vol. 47, no. 3, pp. 268-274, 2011.

[7] S. Zhang and X. W. Li, "Effect of the stress balance on determination of rock dynamic fracture toughness using holedcracked flattened Brazilian disc," Applied Mechanics and Materials, vol. 117-119, pp. 71-76, 2011.

[8] J. Xu, S. Dong, and Z. Wang, "Theoretical analysis of effects of confining pressure on the stress intensity factors for cracked Brazilian disc," International Journal of Applied Mechanics, vol. 7, no. 3, pp. 151-155, 2015.

[9] Y. E. Jianhong, "Airy stress function method for analytic solution of stress field during Brazilian disc test," Journal of Engineering Geology, vol. 17, no. 4, pp. 528-532, 2009.

[10] S. K. Kourkoulis, C. F. Markides, and J. A. Hemsley, "Frictional stresses at the disc-jaw interface during the standardized execution of the Brazilian disc test," Acta Mechanica, vol. 224, no. 2, pp. 255-268, 2013.

[11] S. F. Wang, Y. Tang, and S. Y. Wang, "Influence of brittleness and confining stress on rock cuttability based on rock indentation tests," Journal of Central South University, vol. 28, no. 9, pp. 2786-2800, 2021.

[12] S. M. Dong, Y. Wang, and Y. M. Xia, "Stress intensity factors for central cracked circular disk subjected to compression," 
Engineering Fracture Mechanics, vol. 71, no. 7-8, pp. 11351148, 2004.

[13] K. T. Chau and X. Wei, "Finite solid circular cylinders subjected to arbitrary surface load. Part I - analytic solution," International Journal of Solids and Structures, vol. 37, no. 40, pp. 5707-5732, 2000.

[14] K. Thuro, R. J. Plinninger, and S. Zah, Scale Effect in Rock Strength Properties, Helsinki University of Technology Finnish National Group of ISRM, Espoo, Finland, 2001.

[15] Y. Yu, "Questioning the validity of the Brazilian test," Chinese Journal of Rock Mechanics and Engineering, vol. 24, no. 7, pp. 1150-1157, 2005.

[16] W. C. Zhu and C. A. Tang, "Numerical simulation of Brazilian disk rock failure under static and dynamic loading," International Journal of Rock Mechanics and Mining Science, vol. 43, no. 2, pp. 236-252, 2006.

[17] J. J. Meng, P. Cao, and K. Zhang, "Brazil split test of flattened disc and rock tensile strength using particle flow code," Journal of Central South University, vol. 6, pp. 2449-2454, 2013.

[18] J. Wang, S. H. Li, and D. Zhou, "A block-discrete-spring model to simulate failure process of rock," Rock and Soil Mechanics, vol. 8, pp. 2355-2362, 2013.

[19] C. F. Markides and S. K. Kourkoulis, "Naturally accepted boundary conditions for the Brazilian disc test and the corresponding stress field," Rock Mechanics and Rock Engineering, vol. 46, no. 5, pp. 959-980, 2013.

[20] C. F. Markides, D. N. Pazis, and S. K. Kourkoulis, "Stress intensity factors for the Brazilian disc with a short central crack: opening versus closing cracks," Applied Mathematical Modelling, vol. 35, no. 12, pp. 5636-5651, 2011.

[21] Q. Zhang, X. P. Zhang, and P. Q. Ji, "Reducing the anisotropy of a Brazilian disc generated in a bonded-particle model," Acta Mechanica Sinica, vol. 34, no. 4, pp. 716-727, 2018.

[22] W. Hua, Y. Li, S. Dong, N. Li, and Q. Wang, “_T_-stress for a centrally cracked Brazilian disk under confining pressure," Engineering Fracture Mechanics, vol. 149, pp. 37-44, 2015.

[23] C. F. Markides and S. K. Kourkoulis, "The influence of jaw's curvature on the results of the Brazilian disc test," Journal of Rock Mechanics and Geotechnical Engineering, vol. 8, no. 2, pp. 127-146, 2016.

[24] S. K. Kourkoulis, C. F. Markides, and P. E. Chatzistergos, "The standardized Brazilian disc test as a contact problem," International Journal of Rock Mechanics and Mining Sciences, vol. 57, pp. 132-141, 2013.

[25] D. Li and L. N. Y. Wong, "The Brazilian disc test for rock mechanics applications: review and new insights," Rock Mechanics and Rock Engineering, vol. 46, no. 2, pp. 269-287, 2013.

[26] Z. L. Zhou, Y. Zou, X. B. Li, and Y. H. Jiang, "Stress evolution and failure process of Brazilian disc under impact," Journal of Central South University, vol. 20, no. 1, pp. 172-177, 2013.

[27] M. D. Wei, F. Dai, N. W. Xu, and T. Zhao, "Experimental and numerical investigation of cracked chevron notched Brazilian disc specimen for fracture toughness testing of rock," Fatigue and Fracture of Engineering Materials \& Structures, vol. 41, no. 1, pp. 197-211, 2018.

[28] M. R. M. Aliha and M. R. Ayatollahi, "Rock fracture toughness study using cracked chevron notched Brazilian disc specimen under pure modes I and II loading - a statistical approach," Theoretical and Applied Fracture Mechanics, vol. 69, pp. 1725, 2014.
[29] R. Chen, F. Dai, J. Qin, and F. Lu, "Flattened Brazilian disc method for determining the dynamic tensile stress-strain curve of low strength brittle solids," Experimental Mechanics, vol. 53, no. 7, pp. 1153-1159, 2013.

[30] M. Cai, "Fracture initiation and propagation in a Brazilian disc with a plane interface: a numerical study," Rock Mechanics and Rock Engineering, vol. 46, no. 2, pp. 289-302, 2013.

[31] M. Abshirini, N. Soltani, and P. Marashizadeh, "On the mode I fracture analysis of cracked Brazilian disc using a digital image correlation method," Optics and Lasers in Engineering, vol. 78, pp. 99-105, 2016.

[32] N. W. Xu, F. Dai, M. D. Wei, Y. Xu, and T. Zhao, "Numerical observation of three-dimensional wing cracking of cracked chevron notched Brazilian disc rock specimen subjected to mixed mode loading," Rock Mechanics and Rock Engineering, vol. 49, no. 1, pp. 79-96, 2016.

[33] F. Dai, Y. Xu, T. Zhao, N. W. Xu, and Y. Liu, "Loading-ratedependent progressive fracturing of cracked chevronnotched Brazilian disc specimens in split Hopkinson pressure bar tests," International Journal of Rock Mechanics and Mining Sciences, vol. 88, pp. 49-60, 2016.

[34] Y. Xu, F. Dai, T. Zhao, N. W. Xu, and Y. Liu, "Fracture toughness determination of cracked chevron notched Brazilian disc rock specimen via Griffith energy criterion incorporating realistic fracture profiles," Rock Mechanics and Rock Engineering, vol. 49, no. 8, pp. 3083-3093, 2016. 